\title{
The Politics of Transport in the Perspective of Land Transport Policy (A Case Study in Indonesia)
}

\author{
Bambang Istianto ${ }^{1,2}$ \\ ${ }^{1}$ The Institute of Land Transport, Bekasi, Indonesia \\ ${ }^{2}$ The Institute of Social Science and Management of Stiami, Jakarta, Indonesia
}

\section{Email address:}

bambang.istianto58@gmail.com

\section{To cite this article:}

Bambang Istianto. The Politics of Transport in the Perspective of Land Transport Policy (A Case Study in Indonesia). Social Sciences. Vol. 4, No. 6, 2015, pp. 142-149. doi: 10.11648/j.ss.20150406.13

\begin{abstract}
The Term of Transport politics has relation between politics and transport. Carrying out a research on transport politics in the perspective of transport policy aims to develop the idea of building a new paradigm of transport politics which is expected to be able to solve the problems of the formulation and the implementation of the land transport policy in Indonesia. This research is using the Method of qualitative research based on the qualitative-descriptive analysis on transport politics. The approach to knowing the concept of transport politics is based on the pattern of definitive concept, paradigm, sensitivity theory, Value-chain Management and input-output model in the policy process. The result of the research shows that the paradigm of transport politics becomes a dominant variable in the formulation and the implementation of the land transportation in Indonesia.
\end{abstract}

Keywords: Politics Transportation, Transport Policy, Public Service Transport

\section{Background}

The term "Transport Politics" (Politics of transportation) is almost never discussed by the experts and the practitioners of transportation in Indonesia, its presence is unfamiliar and still strange. The discussion about the political relations and transportation for practitioners has not possibly occurred and maybe no urgency and relevance. Although in developed countries such as the United States, Europe, Australia, and others, the transport politics has long enough become a study, and the study materials have been applied in any transport policy which has been integrated in a multi disciplinary approach. So far, the "paradigm" in the transportation perspective has been more considered as a service product that is closer to the matters of "Economy" and loaded with sophisticated "Technology" and the calculation of "Mathematics". In the development of the "Transport" as a science, it can only be seen clearly through the approach of engineering science and economics. Therefore, the role and the function of transportation defined as a promoting and service sector as well as the "Derived Economy" and the "Leading Sector", or in the wider sense, transportation plays a role as the lifeblood of the development of ideological, political, economic and social culture. However, "the management and the operation of transport services should be" a leading sector, but in its development, the capacity and the authority have declined, so the face of transportation in Indonesia is getting tangled, the reduced role of the "function of transport services" as the leading sector is allegedly due to lack of attention to the multi-disciplinary studies including a study on "transport politics". Essentially, "Transport Technology" Consists of Several types among others: Aircraft, Ships, Cars and trains. Infrastructure as the main supporting component of transportation, the two are mutually-supporting. This means that if "infrastructure" is in line with the needs of transportation, the balance will occur, if it is used for the interest and the needs of the mobility of people and goods, it will be more convenient, safe, smooth, fast and timely. Indeed transport supports the "mobility" of people and goods in the society in order to fulfill their wish of welfare in their life. Therefore, the role and the function of transportation are vital for human life. "the transport sector" is a function of "public services "which becomes the "responsibility" of the government. Thereby the government should be serious and mainly prioritize to build the infrastructure and the means of transport in accordance with the needs of society. Empirically it is widely found that the both phenomena are inadequate to support the national economic growth and the national integration as the outermost islands are still vulnerable to annexation by the neighboring countries. 
Besides, transport technology that is growing rapidly can be a means of building social engineering. Transport Technology is able to make changes to the attitudes, behavior, and actions of humans individually and collectively (in groups) as required by technology. But in fact the phenomena of social engineering process especially in Indonesia often face failure in realizing the application of transportation technology. The application of transportation technology policies such as "Traffic Demand Management" (Three-in-one, road pricing, Mass Rapid transit (MRT), Pedestrian bridges, school safety zones), has not been able to change people's behavior as well. The failure of the implementation of the Transportation Technology policies, when analyzed carefully, was not lain solely on the technological issues but has shifted to the issues of being "non-technical".

The Growth and the development of Metropolitan cities in almost all regions in Indonesia actually experienced the negative growth called "Urban sprawl, namely the irregular and chaotic urban growth. Though theoretically "transport" functions to form "cities" which are organized, orderly, and artistic. Therefore, so far it has become a daily sight - the land transport chaotic conditions become complicated and worrisome.

A world-class scientist "Francis Fukuyama" in Arys Hilman, (2010) in the book of State Building Governance and World order In The 21st Century for saying: "Fukuyama" tells the story about Americans who often complain about the traffic regulations in the country of cowboys. Those who complain, he thinks, should go to "Jakarta" to find out the facts that the infirm regulations would produce a more terrible situation. Thus, the above phenomenon indicates that the "social engineering" should be supported by "social participation". There the non-technical issues are to trigger the experts and the practitioners of Transport, In view of the transport problem in a more comprehensive and systemic way, they need to be supported with a multidisciplinary approach such as the support of analysis tools of political science, sociology, psychology, law and administration. The contribution of "transport politics" is able to explain what, why, and how a transport policy can run well, with the broad support from various elements of society and government institutions of various levels previously therein filled with a variety of interests that have interacted with one another dynamically such as cooperation, competition and even conflict.

\section{Basic Concept of Transport Politics}

\section{a. What is Transport Politics?}

"Transport Politics" is the study of the process of efforts (struggles) in the competition arenas of the various power interests (authorities) associated with the management of transportation in order to be integrated into a single authority (policy makers) in case of organizing the wider interest of the people (National Interest); that is to open opportunity to access to economic and national development as well as creating the transportation services that are safe, convenient, fast, and timely. b. Why is the thought of "transport politics" emerging?

The problems which are increasingly complex and worrying are the growing of motorcycles in all the cities (towns) in Indonesia. They are used as a means of transportation to replace public transport. The use of Motorcycles as a means of transportation causes the social impact as well as the traffic accident much greater than when using public transport such as buses, metrominis, mikrolets, (public vans). The booming trend of using the motorcycles as the replacement for public transport by the people (public) indicates the inter - sector policy that does not synchronize well and finally it less supports the role of the managers of transportation services. This will influence especially the economic sector, even a country will less run well, other sector growths will be purely influenced too. Otherwise, the transport function supports the growth of the national economy. (see: figure I) The relationship between the transportation and the national economy).

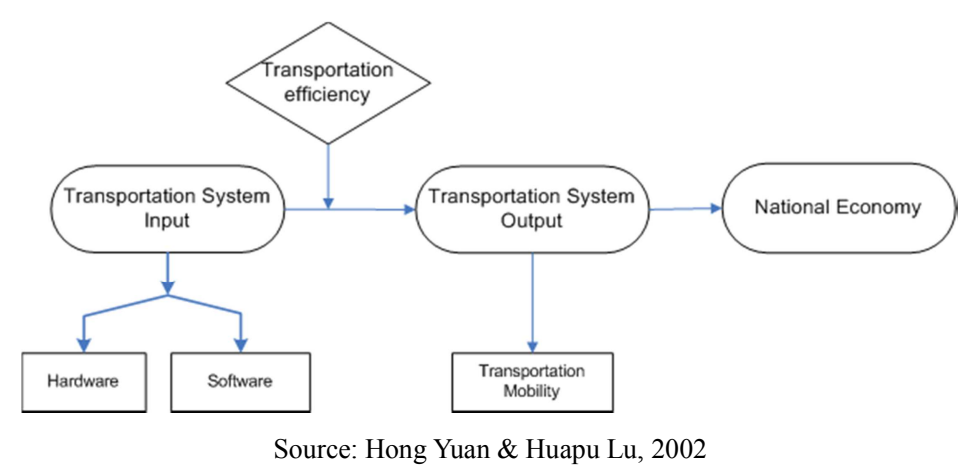

Figure 1. Relationship Between The Transportation and the National Economy.

Figure 1 above, as already described, inspires that the link between efficiency and effectiveness of the transport to the national economic growth is very strong. Because of the optimal role of transport, it is able to provide the acceleration and movement of goods and people. Therefore, the orientation towards the optimal use of public transport becomes a key policy agenda in arranging the transportation system in
Indonesia. the phenomenon above which shows the "transport problem" has begun to shift to non-technical issues. The diagnosis of the chaotic transportation system in Indonesia very urgently needs policies that are controlled by the supreme authority of the National Government Leader, namely the President, the direct involvement and the synchronization (among) these sectors are needed so that the sector ego can be 
eliminated. The Understanding of the problems above can be thought of as an area of study of "Transport Politics".

c. Paradigm of "Transport Politics"

Paradigm can be the way, the direction and the guidance in building a "theory". Similarly, the paradigm is the foundation and the cornerstone of how people look toward a world problem that can affect the attitudes behavior and human actions. However, the implementation of a theory is not a matter of being right or wrong, it is heavily influenced by the "paradigm" of "Power" Holder. Because building and putting "a paradigm" should be able to bridge the various dynamics of the public interest. According to Patton (1975) in Mansour Fakih (2001,9), "Paradigm is a world view of a general perspective of breaking down the complexity of the real world".

In relation to the transport politics paradigm, it can be formulated as follows:

1. "Transport" is the "basic needs" of society then becomes the responsibility of the state and government to manage, organize and take care of properly.

2. Transport is created from simple to modern / advanced, basically to meet the needs of human life and is able to encourage the mobility of people, goods, and services in order to meet people's welfare.

3. Development of "Transportation Technology" is an instrument that is capable of building and changing the human attitudes, behavior and is often referred to as "social engineering" on the one hand and on the other hand must be supported by "social participation".

4. "Transport" Policy is the commitment of the government (public policy) in an effort to regulate and manage continuously toward the development and improvement in the order to provide the ease of the mobility of people's.

5. Government's Policy in the field of transport in order to run smoothly needs the people's support. For the level of "the formulation and implementation of the policies, the government must always involve "public participation."

6. "Transport Politics" in essence is the efforts in each "Transport Policy Formulation" in getting optimum support, and the government is active and responsive in socializing, communicating, negotiating, bargaining, Lobbying, compromising, and making consensus with the various elements of society in order to build such

a.support. At the level of the implementation of the government's policy, there is always a struggle and defence for "The Transport Policy" in order to run smoothly, successfully and on target.

\section{3. "Transport Politics" Approaches}

Some approaches are expected to be able to explain the relationship between politics and Transport, namely the value chain analysis approach Sensitivity theory approach, and input-output model approach. Each approach can be described as follows:

\section{a. Value chain analysis approach}

This approach is usually used in the "managerial economics" that aims to control the variable cost. Starting from the chain of upstream to downstream activities, the strategic values of the chain can be set at a very decisive action to the financing "effect". This should be fully controlled through the support of a stronger authority. While according to Willem Siahaya (2013) referred to as the "Supply Chain Management", it is the integration of the competent business resources of the flow of goods, the management of procurement and the logistic activities as well as the related information from the origin to the point of consumption including the coordination and collaboration with channel partners (suppliers, manufactures, transporters, distributors, retailers and customers) for the purpose of conforming to customers "requirements".

The thought above can be adopted to conduct an analysis of "Transport Politics" to the chain of the implementation of "Land Transport" which has a complex cross-sector relationship level, it can be described as follows: if the transport functions as a "Promoting and Service Sector", then "Promoting" is placed as upstream and "Services" as downstream. The "promoting sector" activities are ranging from the availability of transport infrastructure, transportation, design and motor vehicle prototype (performed by the Ministries of infrastructure, Industry, Research and Technology). While the "service sector" is from the management. The regulation and the maintenance of transportation facilities are efficiently and effectively carried out by the Ministry of Transportation. The order and security of the transport Management and Law enforcement are done by the Police. a series of chains ranging from upstream to downstream of the implementation of "Road Transport" can be analyzed with a theoretical approach "Value chain". Analysis of the overall chain contains "strategic and fundamental values, especially the position of" transport functions "as a Leading Sector". The link above shows that the "implementation of land transport 'has a role as a leading sector having very fundamental problems, among others, the upstream chain (promoting sector) does not always have the vision and mission which are in line with the vision and mission of the Downstream chain (service sector). The absence of synchronization in fact causes the transport system not to be effective.

The problem in fact is still not resolved properly and is required a more intrinsic understanding through the study of "Transport Politics", in order that the Function of Transport can be realized optimally.(See: Figure 2 below)

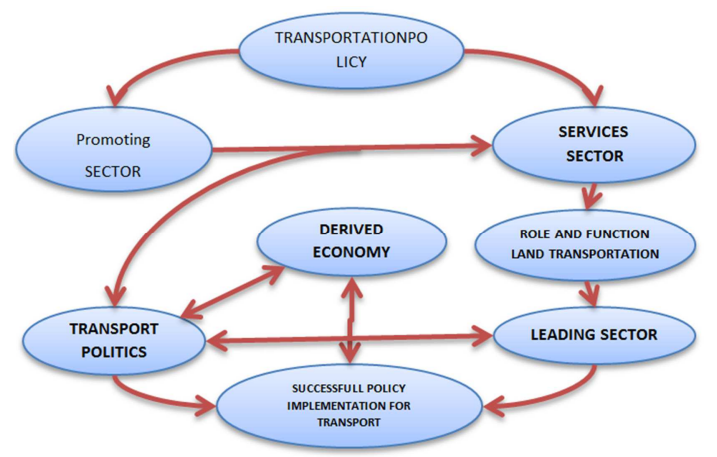

Figure 2. Role and Function of Land Transportation in the Perspective of Transport Politics. 
Figure 2 above shows that the transport policy is in fact through a long process. The role and the function of the leading and promoting sectors in the chain are the core business, the synchronization and the integration with other sectors are required so that the formulation and the implementation stages can proceed smoothly. The successful implementation of transport policy will be able to provide transportation services that are safe, comfortable, cheap and punctual.

\section{b. Sensitivity Theory Approach}

This approach is a theory that is used for the purpose of the variable cost efficiency in conducting The "total integration" towards the "chain of events" that greatly affect the efficiency costs. it refers to the theory of analyzing the "chain" Implementation of the land transportation, the Ministry of Transportation should be able to synergize and integrate the vision and mission of the Ministry of Infrastructure, Industry, $\mathrm{u}$ as well as Research and Technology, the vision and mission managers and the providers of transportation services (The Function Service Sector). The sinergy and the Integration of the vision and mission of the into the preparation of the concept of the "Master Plan" and the Strategic Plan as well as the Action Plan are very influential on the establishment of an efficient and effective transportation service. The integration between upstream and downstream chains in order to be consistent and harmonious requires the support of a higher authority, so that the function of the land transport is capable of acting as a "leading sector". Efforts to explain the understanding of the institutional problems in establishing and reviewing the vision and mission of the transport need to be supported by the study of Transport Politics.(See Figure 3 below)

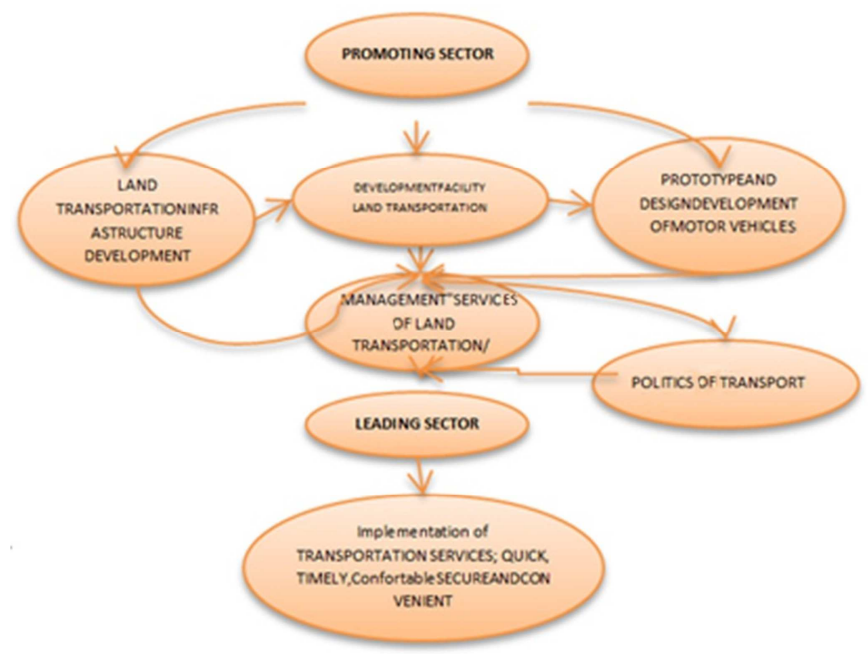

Figure 3. Role of Land Transportation as a Leading Sector.

Based on the explanation of the sensitivity theory approach above, a role as a leading sector is to integrate the strategic elements which are very susceptible to the disruption of the core business chain of transportation such as infrastructure, land use, and traffic management.

c. Conversion of Input into Output Model Approach

The Conversion of Input into output model approach is often used to describe the process of policy formulation. If a policy needs to have a strong legitimacy in accordance with the aspirations of the fight for the birth of the policy then it is a must to build the input power and strengthen the support in the process of aggregation in order that the output policy is in accordance with the aspirations. The input strength is often referred to as a process of "articulation" which has two strengths, namely "Demand" and "Support" while the "Conversion" is referred to as a process or function of"aggregation." The aggregation process will result in "alternatives" of the policy until the output process, namely the determination to the birth of "a new policy" (decision making process). "The new policy" when implemented will get a Positive or a negative reaction from the public. The response will be a "feedback" in the form of demands and supports and so on. The input strength played by all elements of society, including the "government" (infrastructure and supra-political structure). While the "Conversion" is played by the executive and legislative (supra political structure) that run the aggregation. With the conversion of input into output model approach, the study of "Transport Politics" can contribute to the thought of analysis toward the appropriate policy formulation in the transportation. The study of "Transport Politics" is expected to encourage efforts at the level of "policy formulation" in accordance with the aspirations of the ministry of Transportation Directorate General of Land Transportation to build the supports of power of the various elements so, when bringing the aggregation into a "policy", it has strong legitimacy. (see: Figure 4 below)

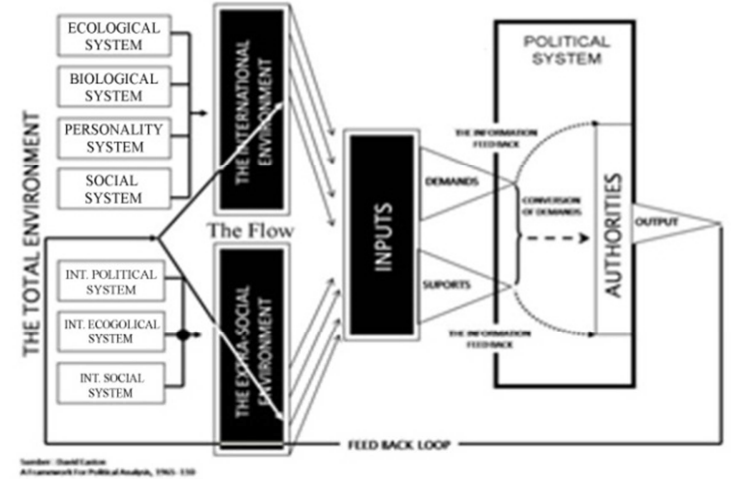

Figure 4. A Dynamic Response Model of A Politucal System.

\section{Institutional Analysis of Land Transportation Function}

Institutional or commonly known as an institution is a social unit that includes an interaction of individuals within the framework of the cooperation process and each carries out activities in accordance with the division of labor (Distribution of Work) which has been determined in an organizational structure in order to achieve the goals set. Through an organization, a whole series of activities in a function can be controlled in an orderly and regular way against all the potentials owned by the organization both 
human resources and other resources. Related to the study of "Transport Politics", institutionally the function of land transport "becomes one of "the units of analysis for the institutional characteristics of transportation which have a high potential for the conflict of interest. As it has been described above, in principle the establishment of an efficient and effective organization is that each structure can accommodate various types of functions, but a function can not be run by a variety of structures. Therefore, if the functions are performed by the various structures, there will be "miscoordination and miscommunication" and could even be a conflict in the implementation of operational activities. As it is known, the institutional function of land transport based on the law number 22 of 2009 on road traffic and Transport, has characteristics as mentioned above. Transportation as a system in the legislation has set five (5) institutions which have the authority associated with the transport function. For example,the Transport Infrastructure Provider (Ministry of Infrastructure), The Transport Facility Provider (Ministry of Industry), The motor vehicle prototype and design provider (ministry of Research and Technology), "Land Transport Services" Operator (Ministry of Transportation). While the Law Enforcement and traffic management by the National Police. The Institutional positions as mentioned above show that "Transport Function"as a Systemic being" having the Complexity" in the government management, which is vulnerable to miscoordination and mis communication in managing the land transport function. The example of the formation of the "Traffic Forum" In The smaller towns is less effective due to the mechanism of integration and synchronization in the operational activities. the institutional problems or dilemmas can be seen below. The complex relationship of the government management including both the technical and management aspects of the five institutions of the government is interesting to study in the perspective of "Transport Politics". The contribution of the analysis in the study of "Transport Politics" toward the Institutional Position of the "Land Transport Function " as a systemic being can be formulated as follows:

a. Through the study of "Transport Politics", the "conflict map" that occurs at the policy level and the operational level in the organization of "land transportation" which involves the five government institutions can be identified.

b. A review of the control mechanisms that integrate the various interests of the five Government institutions, such as the "Traffic Forum" can function effectively.

c. Identifying the sources of the demands and the supports of the elements of society to the implementation of road transports policies caused by the discrepancies among the five Government Institutions in drafting the master plan and. the operational technical policies of each of these institutions.

d. A review of the implementation of land transport as a "Leading Sector" is to provide a more powerful "Authority" to integrate the various interests.

By looking at the institutional conditions of the land transport function as seen in Figure 5. Of the four studies on the contribution of the analysis tools of transport politics that can be the input for the land transport providers in order to encourage the anticipatory and responsive attitude toward the transportation Problem caused by the condition of the position of the institutional relations of the complex transport function. Empirically The Function of Transport carried out by a variety of structures of other institutions and being non-subordinate will be strongly miscoordinated. Thus, the institutional relations among the Ministry of Transportation, The Ministry of infrastructure, The National Police, the Ministry of Industry and, The Ministry of Research and Technology if they are harmonious and synchronized it will be certain that the services of particularly land transport will become more satisfactory for the wider community. Traffic Congestion and chaos on highway have already begun in the cities that are growing and developing throughout Indonesia. Therefore, the institutional problems that have been structured in the legislation are now for the highest authorities of the government to take a measured and systematic action. Institutional restructuring of transport to facilitate the strategic functions of the land transportation needs to be done, although the legislation must be revised. The logical and rational thinking can bridge the sectoral ego as having been encountered so far. The Institutional complexity of the land transport function as seen in figure 5 below.

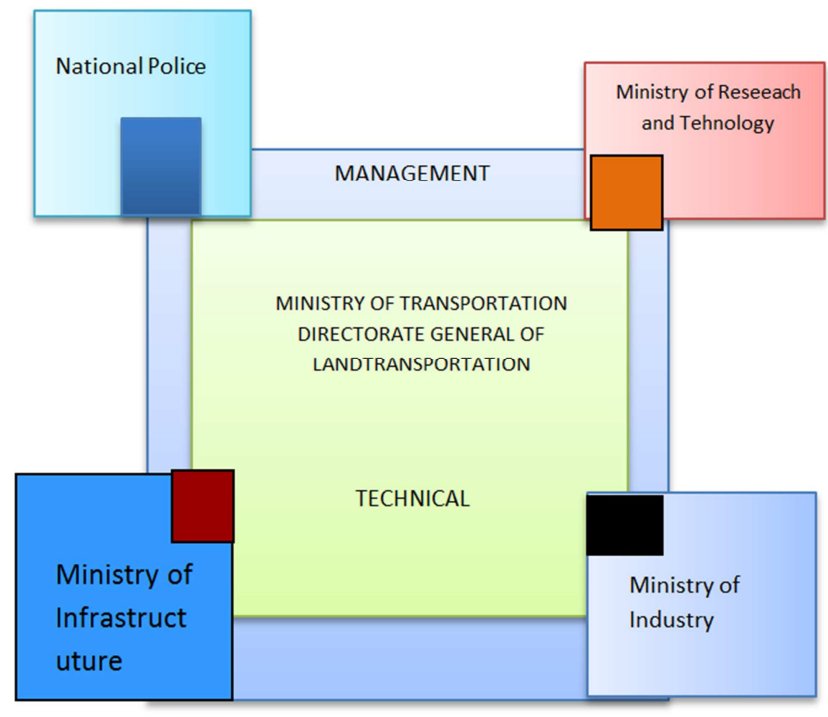

Figure 5. Multiauthorities in transport function.

The Explanation of the institutional analysis of the existing transportation function showing that "one of the highway transportation functions carried out by more than one structure" has been proven empirically that the miscoordination may potentially occur. The implementation of the Law Number 22 of 2009 on Road Traffic and Transport has been six years, In fact, running less optimal. The existence of road transport infrastructure has not been fully supportive of the optimization of the transport function. The traffic management is not synergistic in its implementation so that chaos and traffic jams have occurred in large and medium cities even growing cities throughout Indonesia. The booming of motorcycles throughout Indonesia and the tendency to 
change the function as a means of transportation have the impact toward the four-wheel public transport to be facing collapse. Where the role of public transport is not running optimally and the transport function is less efficient, The economic stability will be disturbed.

\section{Relations of "Transport Politics" to "Land Transport Policy"}

The relationship between transport politics and land transport policy as mentioned above is a new topic and not easy to build the two variables as an embryo into an independent science, it needs deep excavation or exploration of the concepts, methodology, and the proper approach. However the attempts to draw up a description of both sciences that can be considered relevant in the search for the relationship between politics and Transport have already been a significant improvement. Besides it can contribute ideas that may yet be revealed or disclosed by the transportation experts about transport issues in the political perspective, it also adds an insight and a new repertoire for political experts and transportation experts. The compound of the two sciences can be extracted continuously until it finds a concept, methodology and techniques as well as methods of approach that can be justified scientifically. If the transport politics is able to build a proper analysis instrument as a multidisciplinary approach, it is expected to be a diagnostic tool appropriate to the complex problems of transportation in Indonesia. As it was mentioned above, the emergence of the thought of "Transport Politics" is based on the phenomenon of failure at this stage in the formulation and implementation of the Land Transportation Policy. As described above, the complexity of transport "is considered" not to be caused by the factors of "technology" and the economy, but rather "non-technical". Non-technical factors are closer to the issue of "human" with the various dimensions of the society. Social dimension can be seen from the standpoints of sociology, politics, social psychology, law and administration. The dimension from the standpoint of "politics" will contribute to the unit of analysis from the aspect of "rule" or public policy. From the aspect of "power", it inspires that "The success of land Transport Policy should have a strong enough power legitimacy both from the government's support in terms of the sufficient strength of resources and the support from all elements of society at its optimum. Similarly, from the aspect of "Public Policy" ranging from the policy formulation to the Policy Implementation, it receives broad support from all elements of society.

The description above shows the "relation" between politics and transportation, especially if associated with the "Land Transport Policy". The Contributions of "politics" in terms of "policy" implies that the success of a "policy" which receives broad public support should be perfectly prepared with starting from the "policy formulation to the Poly Implementation". Political Science will explain what, why, and how the support of the elements of society can be "energy sources" in supporting the success of a policy. As demonstrated in the above chapter, the "Urban Transport Policy", "Traffic Demand Management "(TDM) and Mass Rapid transit" (MRT) are as a policy strategy to address the" traffic jams "in the Metropolitan cities in Indonesia and particularly in Jakarta. But in fact the policies now are still stagnantly implemented. The presence of "Transport Politics" can explain "what and how the failure or the success of a policy, the extent of the policy formulation and the policy implementation should be prepared in a systematic and complete way. In concept and theory, to prepare the policy formulation can be seen in figure 6 and 7 as a reference. The political dimension of transport through the instrument of analysis based on the concepts and theory will be able to realize the implementation of land transport services that are safe, comfortable, fast, timely, and inexpensive. The relationship between the politics of transport and the Land Transport Policy can be seen in Figure 6 below (source: O. Jones, in Hariyoso, 2002)

\begin{tabular}{|c|c|c|}
\hline PHASE & ACTIVITIES & INITIAL PRODUCTS \\
\hline \multirow[t]{5}{*}{ Government Problem } & $\begin{array}{l}\text { Perception } \\
\text { Definition }\end{array}$ & Problem \\
\hline & Aggregation & Demand \\
\hline & Organization & \\
\hline & Representation & Priorities \\
\hline & Agenda Setting & \\
\hline \multirow[t]{9}{*}{ Government Action } & Formation & Proposal \\
\hline & Research & \\
\hline & $\begin{array}{l}\text { Anaaysis } \\
\text { Selection }\end{array}$ & \\
\hline & Legitimation & \\
\hline & Identification of Interest & Programme \\
\hline & Communication & \\
\hline & Bargaining & \\
\hline & Compromise & \\
\hline & $\begin{array}{l}\text { Appropriation } \\
\text { Formation }\end{array}$ & Budget \\
\hline
\end{tabular}

Figure 6. Public Policy Process.

In the process of policy formulation theoretically the problems are always faced by the government, among others, perception and definition while the demands are in the form of aggregation, organization, representation and agenda setting. The above problems require immediate government actions, among others communication, bargaining compromise and 
others. If at that stage can be done well by the government, so the process of policy formulation will run well. The formulation of the policy in the field of transportation will also face problems as described above. The Transport politics gives the idea that the stages of the "government's problem" and the government's action will always calculate or compute the elements of the supporting forces and opponents. The efforts of the government are to make success in accordance with the public interest. And the elements of support should be enlarged or strengthened. For example, the support element of the political parties, interest groups, NGOs, pressure groups and community leaders. As for the stages of the implementation of the policy, it can be among others, perception and definition seen in Figure 7 below. (source: Rogers: in Hariyoso, 2002)

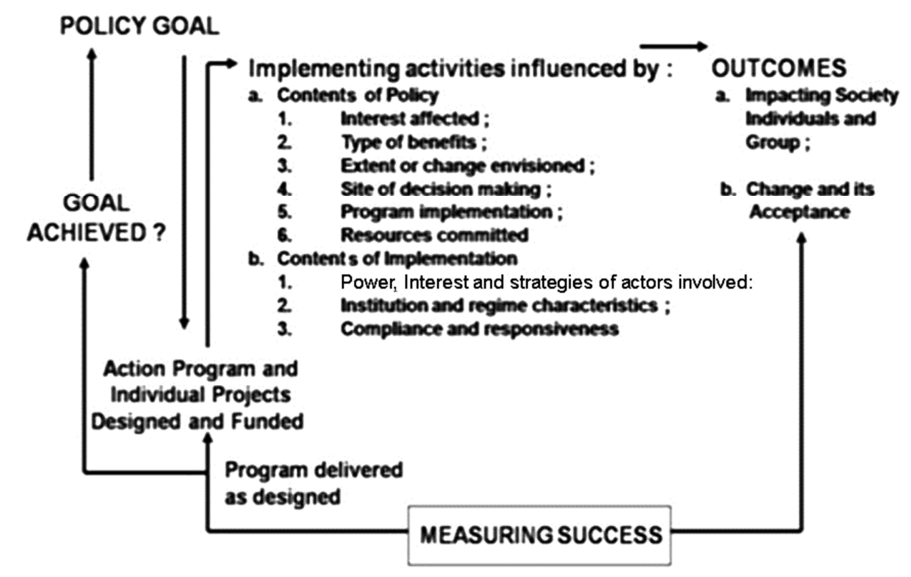

Figure 7. Implementation as Political and Administrative process. (Rorgers, 1991:19)

Being at the conceptual stage of the implementation of the policy will be associated with some other aspects that affect the contents or the substances of the policy, and the elements of society who support and reject the desired changes and budget support for the implementation of the policy and for the measures of success in achieving the policy objectives. The concept and theory above, of course, can be applied to the field of land transport. Political relations to the land transport policy as it is written in figure 8 below, substantially the support of the concept and theory above in the scheme of the implementation of the policy. If it is applied in accordance with the norms, procedures, standards and criteria set, the various policies such as the "traffic demand management" and mass rapid transit "will be successful in the implementation of the policy. In Figure 8 below it shows that the study area of the transport politics is at the stages of policy formulation and Policy implementation. In essence, policy making is a political process, so that political calculations, especially the support and rejection of the elements of both infra and supra-political structures included in the agenda of formulation and implementation. As explained above, if the study of the transport politics is ignored, it has been empirically proven to be in failure to integrate and harmonize the strategic functions of transportation. It causes transportation in Indonesia not to be efficient, and effective. In fact, as stated by Yuan and $\mathrm{Lu}$ (2002), if the transport is not efficient, it will interfere with the, running of the national economy. Whereas in Figure 8 below, it describes the relationship between the politics of transport and the policy of land transport.

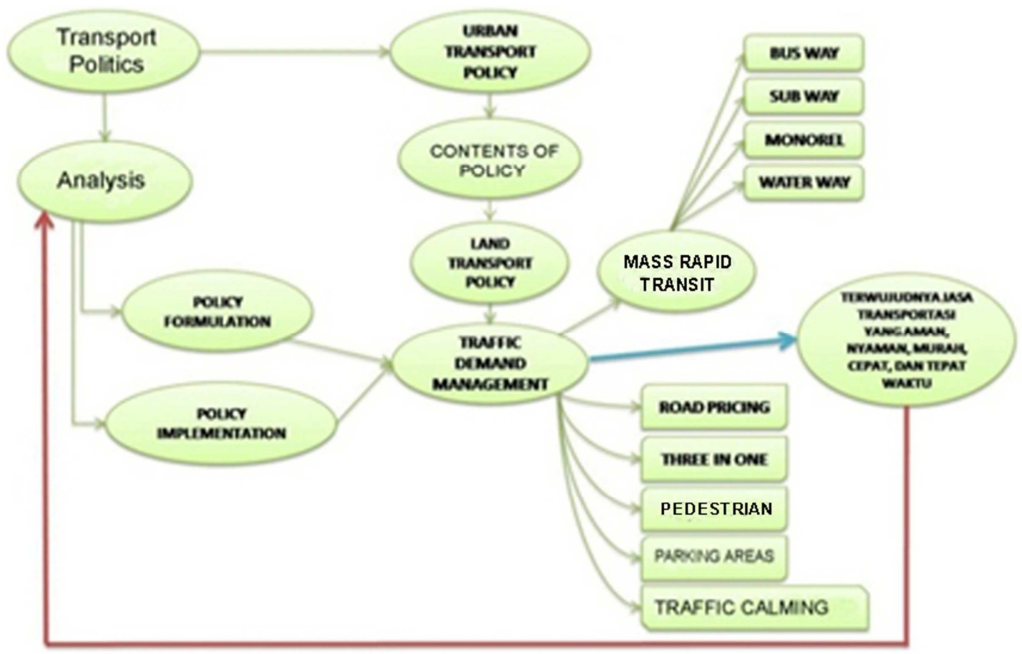

Figure 8. Relationship Between The Politics of Transport and The Policy of Land Transport. 
Based on the explanation above, the politics of transport and the policy of land transport as described in Figure (8) above show a positive relationship. This means that in general when the stage of policy formulation is the process of making laws and regulations, it should be examined comprehensively and calculated carefully. How big is between the support and the rejection of the policy formulation? It should be calculated well in the land transport policy agenda. Similarly, the same thing is done in preparing for the implementation of the land transport policy. In general, the failure at the stage of policy implementation is often less preparation which is comprehensive and systematic, including the assessment aspects of the transport politics. The process of drafting a plan of Board of Transportation Operators of Jakarta, Bogor, Depok, Tangerang and Bekasi (BPTJ) and The Transportation Master Plan of Jakarta, Bogor, Depok, Tangerang and Bekasi (RITJ) established by the decision of the President is a good example in the study of transport politics. The complexity of the phenomena of Jabodetabek transportation problems that has long been not handled properly because of the lack of institutional authority organizing the transport functions. Institutionally, the various trials of implementing the Jabodetabek transportation have been executed but until now they have failed on the stage of policy implementation. The failure of the implementation of Jabodetabek transportation resulted in Jakarta named the "number one most congested city in the World". Thus, the lack of institutional authority of the transport functions can be taken as a good lesson, if the focus of the interest is on the power, it needs to encourage the study of the "Politics of Transport".

\section{Conclusion}

a. Land Transportation Policy phenomenon is not running effectively due to the "non-technical" "factors". Examples of ineffective use of pedestrian bridges, zebra crossing, three in one, road markings and others.

b. One of the non-technical factors is "Political Dimension". The example in the process of formulating the Law number 22 of 2009 Regarding Road Transport Traffic, there was a conflict of interest between the Ministry of Transportation and the National Police Scrambling for the authority of traffic management.

c. The Thought of "Transport Politics" appears motivated by a variety of phenomena in the organization of transportation that has not been efficient and effective because the start of the policy formulation and the policy implementation was not performed optimally. The phenomenon of the traffic congestion on the highway approaching stagnation in Jakarta, Bogor, Depok,
Tangerang and Bekasi (Jabodetabek) is an appropriate example of the above conclusion.

d. One of the focuses of the political assessment is the policy formulation and implementation. The process of drafting the institutional Board of Transportation Operators of Jakarta, Bogor, Depok, Tangerang and Bekasi (BPTJ) and the Master Plan of Transportation of Jakarta, Bogor, Depok, Tangerang and Bekasi (RITJ) as a relevant example in the Study of Transport politics at the stage of policy formulation.

e. Transport politics contributes ideas through the analysis instruments, namely what, why and how a transport policy runs effectively and efficiently and gets the full support of all elements of the society. The implementation of the development process of Mas Rapid Transit (MRT) in Jakarta implemented in 2014 and will be completed in 2018 ranging from Lebak Bulus, South Jakarta to the Hotel Indonesia roundabout in Central Jakarta, is a relevant example of the statement.

\section{References}

[1] Black, John and Lea, John and Parikshit, Danang. (2009). Review of Public Services Obligation In The Transport Sector, Way Forward For Indonesia.

[2] Brian H. Hogwood, and Lewis A. Gone. (1984). the Public Analysis for the Real World. New York: Oxford University Press.

[3] Budiardjo, Miriam. (1997). Introduction to Political Science. Jakarta: PT. Gramedia.

[4] Cracknell, John. (2000) Experience in Urban Traffic Demand Management in a Development Country.

[5] Easton, David. (1965). A Frame Work For Political Analysis, Prentice-Hall; News Jersey.

[6] Fakih, Mansour. (1994). Misguided Thought Theory of Development and Globalization, Jakarta: PT. Raya Grafika.

[7] Hilman, Arys. Sosiologuy. (2010, May 9).

[8] Hong, Yuan and Huapu, Lu. (2001). Evaluation and Analysis of Urban Transport Efficiency in China. the Institute of Transportation Engineering, Beijing: Thinghua University.

[9] Nugraha, D. Rian (2003). The Public Policy: Formulation, Implementation, and Evaluation. Jakarta: PT. Alex Media Komputindo.

[10] Siahaya, Williem. (2013). Success Supply Chain Management, Access Demand Chain Management, Jakarta: Media Publishing. 